\title{
The Production of New Structures from Graphitized Hypereutectoid Steel
}

\author{
S.A. Rounaghi ${ }^{1}$, A.R. Kiani-Rashid ${ }^{2, a}$ \\ ${ }^{1}$ Dept. of Materials Engineering, Ferdowsi Univ. of Mashhad, Mashhad, Iran. \\ ${ }^{2}$ Department of Materials Engineering, Faculty of Engineering, Ferdowsi University of Mashhad \\ Mashhad, IRAN
}

\begin{abstract}
Graphitization process in steels is done during the dissociation of the cementite phase to ferrite and graphite. Since cementite is a metastable phase and graphite is more stable than it, graphitizing transformation occurs during a longer period of time. The presence of alloying elements such as chrome and manganese in common commercial steels results in the necessity of graphitization to be passed at a longer period of time which is not appreciated from the economical viewpoint. However, improving wear resistance and machinability is accounted as one of the main advantages for this process in steels. The final structure obtained after graphitization has been reported mainly as a mixture of ferrite, graphite and a few amounts of cementite. Prolonged annealing time for producing graphitized structure creates a little hardness because of the existence of the ferritic matrix. Therefore matrix has been changed by selecting various heat treatment cycles from ferritic to other types of phases besides new structures that also consist of graphite. Finally their hardness have been measured and compared as a criterion for determining mechanical properties and wear resistance.
\end{abstract}

\section{Introduction}

Graphitization process in steels is accomplished during the dissociation of the cementite phase to ferrite and graphite according to equation 1 [1-7]:

$$
\mathrm{Fe}_{3} \mathrm{C} \rightarrow 3 \mathrm{Fe}(\alpha)+\mathrm{C}(\text { Graphite })
$$

Although graphite is a stable isotope of carbon [8], the meta-stable phase of cementite is often observed in commercial steels which can be explained by inaccessibility to equilibrium conditions or the presence of carbide-stabilizing alloying elements. Figure 1 schematically shows Gibbs free energy for the phases of ferrite, cementite and graphite. In steels containing a certain carbon percentage, $\Delta G$ explains thermodynamically the driving force required for graphitization reaction. In common commercial steels, alloying elements such as chrome and manganese aggregates in carbide phase cause decreasing the cementite free energy [9] and therefore they decrease the graphitization driving force $(\Delta G)$, so graphitization from steels containing these elements entails passing for a long period of time which is not appreciated in economical viewpoint [10-13]. Graphitization in steels mainly occurs from martensitic structure in $600-700^{\circ} \mathrm{C}[14,15]$. According to experimental observations [4-6], martensitic and bainitic structures [16] have been reported as the most susceptible structures for graphitization in steels. Other structures such as pearlitic or spheroidized carbides in ferritic matrix are not kinetically suitable for graphitization.

\section{aemail: kianirashid@gmail.com}

This is an Open Access article distributed under the terms of the Creative Commons Attribution-Noncommercial License (http://creativecommons.org/licenses/by-nc/3.0/), which permits unrestricted use, distribution, and reproduction in any noncommercial medium, provided the original work is properly cited. 


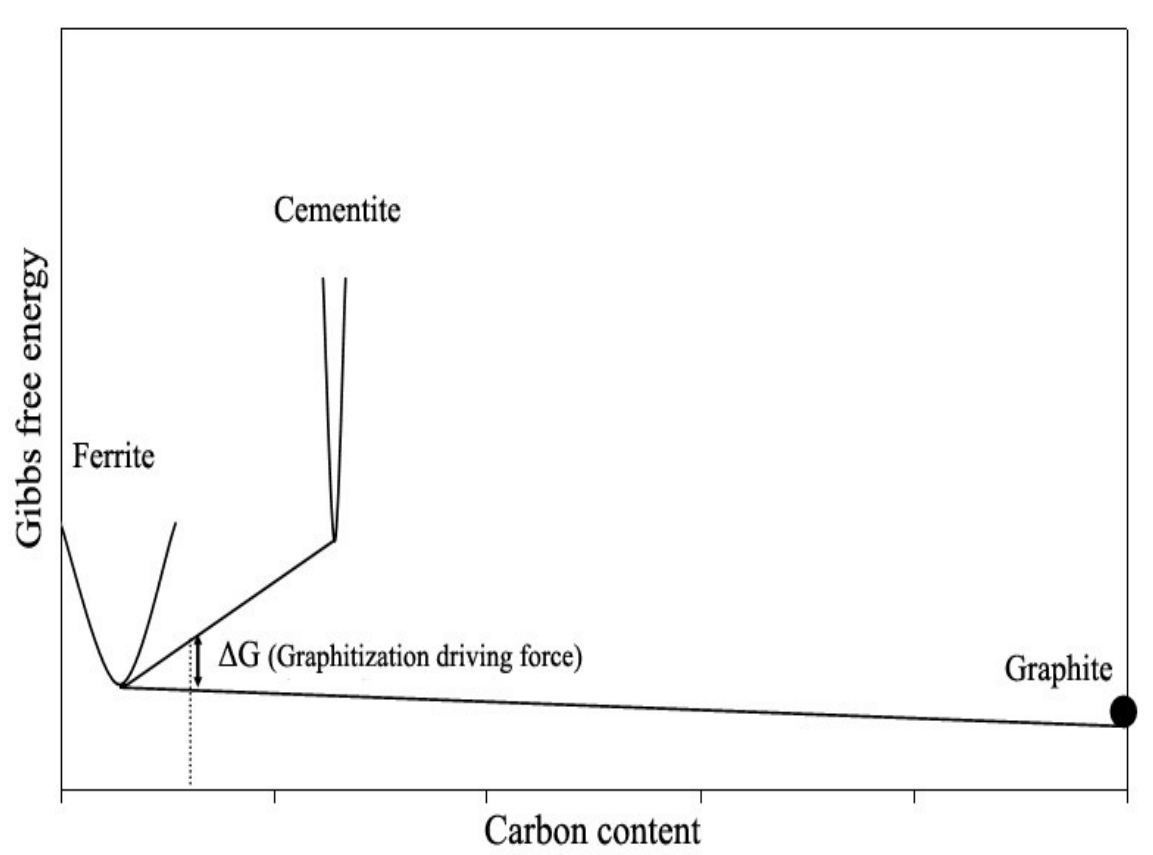

Fig. 1. Schematically Gibbs free energy diagram for ferrite, cementite and graphite phases during graphitization process.

Graphite is a friction decreasing lubricant, therefore, its presence in final structure acts as a parameter for improving wear resistance, machinability and self lubrication of iron alloys [17]. Graphite is considered as the main phase in the structure of numerous cast irons. In this matter, we may refer to remarkable effect of graphite particles on machinability, vibration dumping and heat shock resistance in gray cast irons [18]. In ductile irons, graphite nodules play an important role in improving their toughness and increasing strength comparing with other cast irons [18]. In addition by producing bainitic matrix in this kind of cast irons through austempering process, remarkable changes can be introduced in mechanical and physical properties of these materials [19].

Another application that can be considered for graphitized steel structures is superseding free-cutting steels containing sulphur and lead. These types of steels have harmful effects from the viewpoint of environmental protection due to sulphur and lead addition [20].

The only structure reported after graphitization process in carbon steels is ferritic-graphitic which are observed in microstructure of steels alloyed by elements such as chrome or manganese, also a few amounts of retained carbide $[21,22]$. In spite of positive effect of graphite on wearing properties of steel, ferritic matrix has a low level of hardness due to the long annealing time. These matters causes decrease in the strength and wear resistance of graphitized steel. We can desirably change matrix and protect graphite particles by precise and controlled heat treatment cycles such as cast iron structures. In order to reach this goal, austenitising process is applied in low temperatures being controlled by time. Then samples are cooled in various conditions or immersed in molten lead bath for producing bainitic matrix [23]. Thus, new structures with individual properties are produced from graphitized steel. Finally, it can be mentioned that these kinds of steels have higher mechanical properties such as strength and hardness than graphitized steel.

Table 1. Chemical composition of CK100 steel (weight percent).

\begin{tabular}{ccccccccccc} 
Steel & C & Si & S & P & Mn & Ni & Cr & Mo & Cu & Al \\
\hline CK100 & 0.949 & 0.213 & 0.012 & 0.017 & 0.339 & 0.047 & 0.061 & 0.008 & 0.076 & 0.017 \\
\hline
\end{tabular}




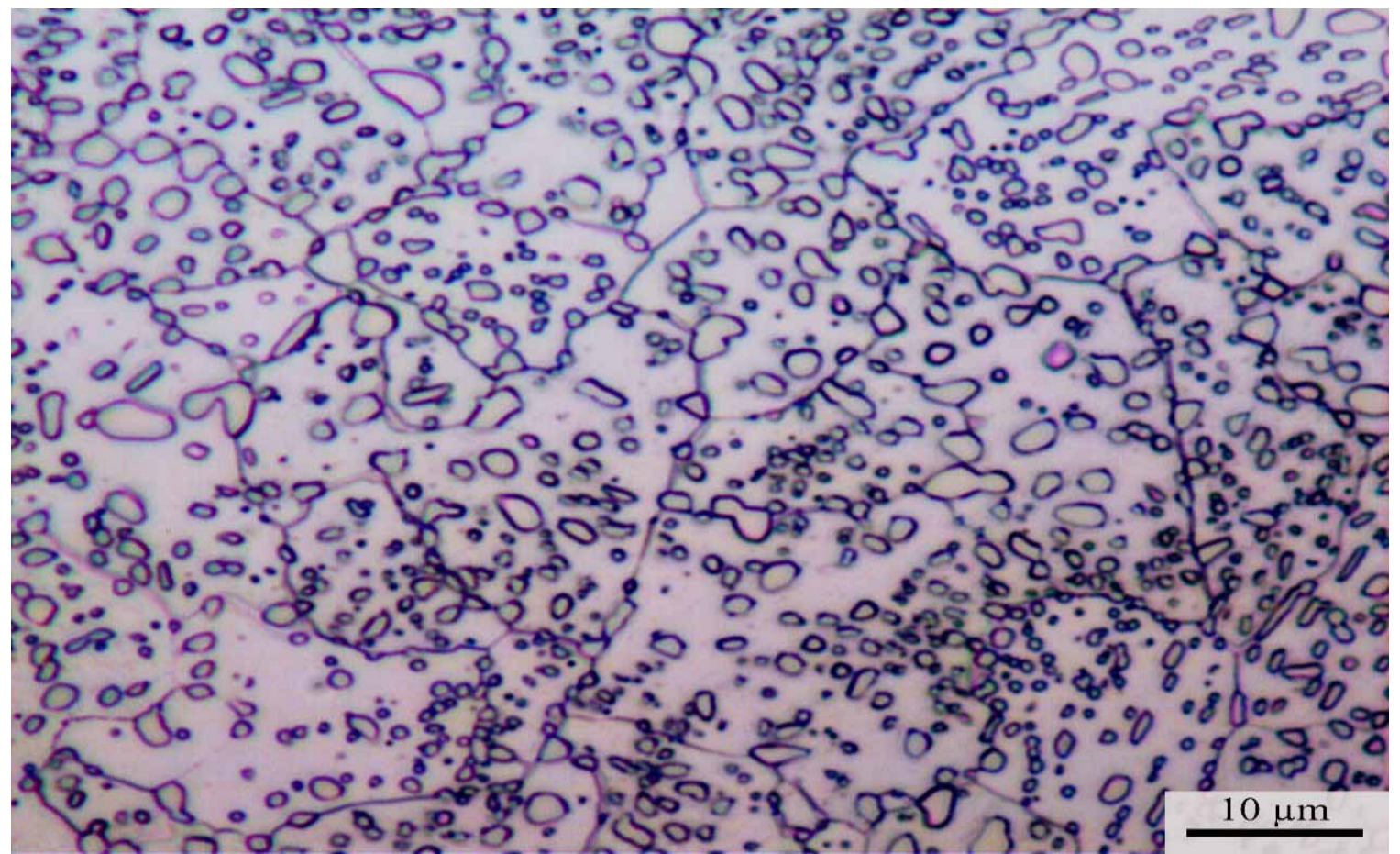

A

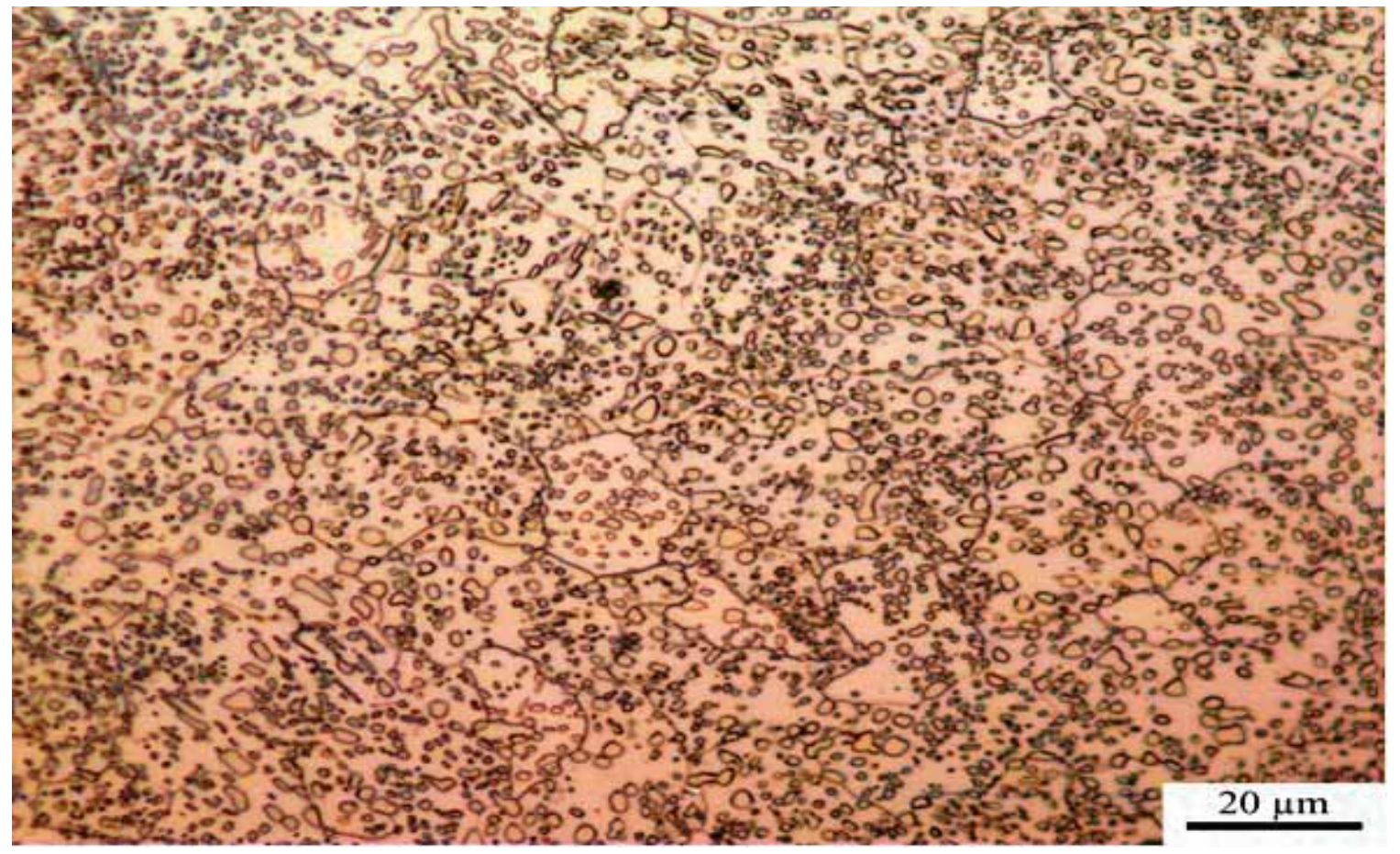

B

Fig. 2. Primary steel structures (as received) consists of ferrite with spheroidized carbides in two magnifications (related to specimen 1). 


\section{Experimental}

The used steel is a low alloyed hypereutectoid steel and its commercial name is CK100 whose chemical composition is listed in Table 1. Primary steel structure (as received) consists of ferrite with spheroidized carbides (Figure 2). Table 2 illustrates heat treatment cycles applied on specimens.

The dilatometric test has been done on cylindrical samples with $4 \mathrm{~mm}$ diameter and $18 \mathrm{~mm}$ length by 2171 Linseis instrument model. Dilatometric samples and other specimens have been prepared from steel (as received) and austentised at $900^{\circ} \mathrm{C}$ for $20 \mathrm{~min}$ to produce the martensitic structure being immediately water quenched. For dilatometric samples, graphitization process from martensitic structure has been done isothermally at $670^{\circ} \mathrm{C}$.

Table 2. Heat treatment cycles applied on hypereutectoid steel.

\begin{tabular}{ccc}
\hline \multicolumn{1}{c}{ Specimen } & Heat treatment cycle & Microstructure \\
\hline $\mathbf{1}$ & As received & $\mathbf{F}+\mathbf{C}$ \\
\hline $\mathbf{2}$ & $900^{\circ} \mathrm{C}, 20 \mathrm{~min} \rightarrow$ water quenched & $\mathbf{M}$ \\
\hline $\mathbf{4}$ & Specimen $\mathbf{2} \rightarrow 670^{\circ} \mathrm{C}, 60 \mathrm{hr} \rightarrow$ air cooled & $\mathbf{F}+\mathbf{C}+\mathbf{G}$ \\
\hline $\mathbf{5}$ & Specimen $\mathbf{3} \rightarrow 820^{\circ} \mathrm{C}, 30 \mathrm{~min} \rightarrow$ water quenched & $\mathbf{M}+\mathbf{A}+\mathbf{G}$ \\
\hline $\mathbf{6}$ & Specimen $\mathbf{3}, 820^{\circ} \mathrm{C}, 30 \mathrm{~min} \rightarrow$ water quenched $\rightarrow 600^{\circ} \mathrm{C}, 2 \mathrm{hr} \rightarrow$ air cooled & $\mathbf{F}+\mathbf{C}+\mathbf{G}$ \\
\hline $\mathbf{7}$ & Specimen $\mathbf{3} \rightarrow 850^{\circ} \mathrm{C}, 15$ min $\rightarrow 400^{\circ} \mathrm{C}, 1 \mathrm{hr} \rightarrow$ air cooled & $\mathbf{F}+\mathbf{M}+\mathbf{G}$ \\
\hline & Specimen $\mathbf{3} \rightarrow 850^{\circ} \mathrm{C}, 15$ min $\rightarrow 250^{\circ} \mathrm{C}, 1 \mathrm{hr} \rightarrow$ air cooled & $\mathbf{F}+\mathbf{M}+\mathbf{G}$ \\
\hline
\end{tabular}

The required time for graphitization in steel specimens has been considered $60 \mathrm{hr}$ at $670^{\circ} \mathrm{C}$. To avoid specimens from decarburization during graphitization, they have been covered by an anti-carburizing coating and then placed in containers with cast iron filings and then cooled in air after graphitization. In the next stage, austenitising process is done in two temperatures, $820^{\circ} \mathrm{C}$ and $850^{\circ} \mathrm{C}$. Austenitising temperature and required time for producing martensitic-graphitic, tempered martensite-graphitic and pearlitic-graphitic structures have been purposed in $820^{\circ} \mathrm{C}$ for $30 \mathrm{~min}$. For martensitic-graphitic specimen, water quenching is done after austenitising immediately. Tempered martensitic-graphitic specimen is tempered at $600^{\circ} \mathrm{C}$ for $2 \mathrm{hr}$ after quenching. After austenitising, pearlitic-graphitic specimen is cooled in air.

To produce bainitic-graphitic structures, austenitising process is done at $850^{\circ} \mathrm{C}$ for $15 \mathrm{~min}$. To produce lower and upper bainitic-graphitic structures, after austenitising, specimens are immersed in molten lead bath with temperatures $250^{\circ} \mathrm{C}$ and $400^{\circ} \mathrm{C}$ respectively and after being held in this temperature for $1 \mathrm{hr}$ they are cooled in air immediately. The hardness test has been done by Koopa instrument according to the Rockwell A scale. In this matter, the hardness test has been done on each specimen for several times and the reported data explains average amount of the specimens (Table 3).

Table 3. Hardness of heat treated specimens according to Rockwell A standard hardness test.

\begin{tabular}{|c|c|c|}
\hline Specimen & Microstructure & Hardness $\left(\mathrm{HR}_{\mathrm{A}}\right)$ \\
\hline 1 & As received & 38.6 \\
\hline 2 & $\mathbf{M}$ & 83.9 \\
\hline 3 & $\mathbf{F}+\mathbf{C}+\mathbf{G}$ & 33.4 \\
\hline 4 & $\mathbf{M}+\mathbf{A}+\mathbf{G}$ & 81 \\
\hline 5 & $\mathbf{F}+\mathbf{P}+\mathbf{G}$ & 60.5 \\
\hline 6 & $\mathbf{F}+\mathbf{C}+\mathbf{G}$ & 59.8 \\
\hline 7 & $\mathbf{F}+\mathbf{M}+\mathbf{G}$ & 69.9 \\
\hline 8 & $\mathbf{F}+\mathbf{M}+\mathbf{G}$ & 68 \\
\hline
\end{tabular}




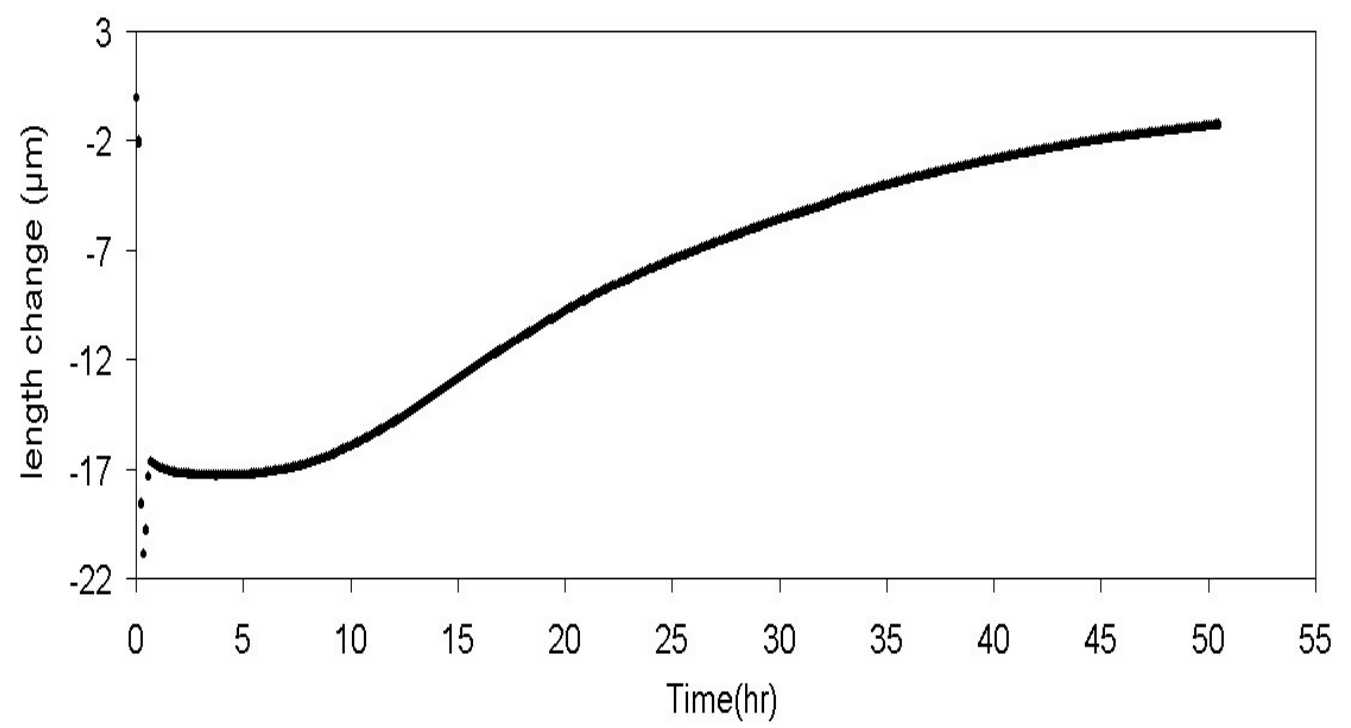

Fig. 3. Dilatometric diagram related to graphitization transformation from martensitic structure at $670^{\circ} \mathrm{C}$.

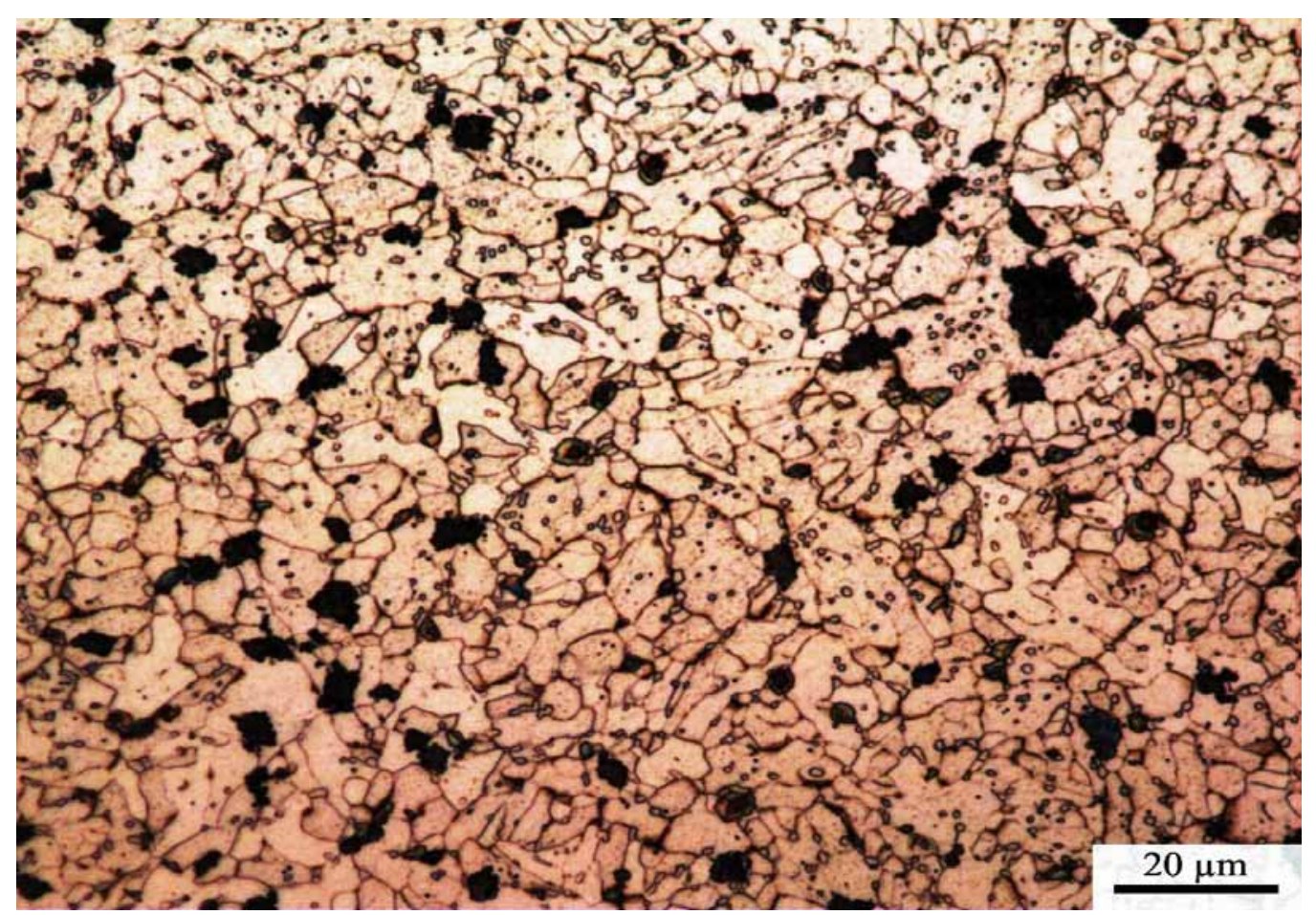

Fig. 4. Graphitized structure consists of graphite particles and retained carbides in ferritic matrix (related to specimen 3). 


\section{Results and discussions}

According to dilatometric test (Figure 3), the required period of time for graphitization in steel specimens from primary martensitic matrix structure has been assumed $60 \mathrm{hr}$ at $670^{\circ} \mathrm{C}$. Figures 4 and 5 illustrate steel structure after the graphitization cycle. In this stage the structure mainly consists of ferritic matrix and graphite particles in grain boundaries with a few amount of retained carbide in microstructure.

According to the iron-carbon phase diagram and steady state zones of cementite and graphite in the experimental steel, austenitising temperature has been assumed a little lower than cementite $\mathrm{A}_{\mathrm{cm}}$ line. In other words, by choosing austenitising temperature at $820^{\circ} \mathrm{C}$, we want to control diffusional transformation of ferrite and graphite with carbide particles to austenite, which is done thermodynamically according to equation 2 to avoid graphite particles dissolution completely.

$$
\mathrm{Fe}(\alpha)+\mathrm{C}(\text { Graphite })+\mathrm{Fe}_{3} \mathrm{C} \rightarrow \mathrm{Fe}(\gamma)
$$

Graphite particles are greater and thermodynamically more stable than retained carbides in graphitized structure, therefore it can be assumed that in low austenitising temperature $\left(820^{\circ} \mathrm{C}\right)$ the carbide phase is dissolved more rapidly in austenite. Therefore, if specimens are quenched immediately in water, austenitic matrix will be transformed to martensite. If specimens are cooled in air from $820^{\circ} \mathrm{C}$, austenite will be transformed to pearlite (Figures 6 and 7). It is necessary to explain that carbon will diffuse into austenite due to the carbide dissolution and modicum carbon transfers from graphite surface, phases with higher percentage of carbon are produced after the cooling stages. These phases remarkably affect hardness and other mechanical properties in the final structure.Martensite is transformed to ferrite with small carbide particles by tempering the martensitic-graphitic structure at $600^{\circ} \mathrm{C}$ for $2 \mathrm{hr}$, (Figure 8).

According to accomplished experiments, austenitising temperature of $820^{\circ} \mathrm{C}$ is not adequate for producing bainitic structures; therefore austenitising at $850^{\circ} \mathrm{C}$ has been applied to achieve appropriate conditions. By using suitable dissolution treatment i.e. by choosing austenitising temperature above the $A_{c m}$ line for $15 \mathrm{~min}$, there have been attempts to control austenitising process kinetically. Figure 9 (images $9 \mathrm{a}$ and $9 b)$ illustrates upper bainite structure with martensite. The dark phase is upper bainite which has nucleated and grown from high energy zones such as graphite particles-matrix interface. The bainitic transformation is not completed, therefore retained austenite in the matrix has been transformed to martensite (bright phase) during the cooling stage. As shown in the Figure, the needle like bainitic-ferrite is observed in the microstructure.

Table 3 shows hardness variants in steel influenced by heat treatment cycles. The highest hardness is related to the martensitic structure before graphitization. Also the lowest hardness is related to the ferriticgraphitic structure because of growing ferrite grains and annihilating lattice defects after prolonged annealing time and also the presence of graphite as a soft phase in the microstructure. Other produced structures have hardness values between these two limits. The results show that the hardness of all of the specimens is higher than ferritic-graphitic structure. In addition, these structures have a wide range of hardness which can be applied according to different conditions and requirements. Similarity of the hardness values in upper and lower bainitic structures can be explained by the presence of martensite phase in the area between upper bainite and its effect on increasing hardness. This means that insufficient time for completing upper bainite transformation causes the enhancement of hardness in this specimen. Due to the increased hardness in other structures containing graphite and also unalloyed investigated steel, hardness variation can be a criterion for strength values. In other words, increasing strength can be expected by increasing hardness in new produced structures with graphite particles compared to ordinary ferritic-graphitic structure.

\section{Conclusions}

Graphitized steel exhibits good wearing properties due to the presence of graphite phase. However, the graphitized steel with a ferritic matrix phase has low hardness and strength which is caused by prolonged annealing time. In this research attempts have been done to replace the ferritic matrix phase by other metallic 
matrixes with superior mechanical properties. To avoid the dissolution of graphite particles in austenitising heat treatment of the specimens, this process has been done at a lower temperature being controlled in a short period of time.

The results show that all of the new structures produced from graphitized steel exhibit higher hardness than the primary graphitized steel.

The structures produced from graphitized steel include a wide range of hardness which can be applied according to different conditions and requirements.

Experiments show that by increasing isothermal heat treatment time in bainitic formation range, the volume fractions of these phases have been changed remarkably which explains diffusional transformation in this range.

\section{Acknowledgment}

A major part of this work was carried out at Ferdowsi University of Mashhad laboratories. We appreciate Partsazan Industries for their assistance in providing some light optical microscopic images. In addition the authors wish to express special acknowledgment to Dr. F. Fazeli for his helpful ideas and discussions.

\section{References}

[1] J.H. Andrew, H. Lee, J. Iron Steel Inst. 165, 145 (1950).

[2] G.V. Smith, B.W. Royle, Trans. ASM 48,320 (1955).

[3] A. Rosen, A. Taub, Acta Metall. 10501 (1962).

[4] H. Sueyoshi, K. Suenaga, Rev. Soc. Jap. Met. 42676 (1978).

[5] L.E. Samuels, Optical Microscopy of Carbon Steels, ASM, Metals Park, 1980.

[6] F. Ternon, Sv. Techn. Aerosp. Rep. 23, 21 (1983).

[7] V.I. Bidash, A.I. Prikhod'ko, Met. Sci. Heat Treat. 29116 (1987).

[8] H. J. Goldschmidt, Interstitial alloys. Butterworths, London 4, 41, 114 (1967).

[9] A. A. Zhukov, News in Graphitization Theory. Thermodynamics of Graphitizing Iron Alloys, UDC 621.1.016.7:669-153.77.001.1 (Nov. 1984).

[10] C.R. Austin, M.C. Fetzar, Trans. ASM 35 485(1945).

[11] R.H. Hickley, A.G. Quarrell, J Iron Steel Inst 178 337(1954).

[12] G.T. Higgins, G.V. Jeminson, J. Iron Steel Inst. 203 , 146 (1965).

[13] J.E. Harris, J.A. Whiteman, A.G. Quarrel, Trans. AIME 233168 (1965).

[14] M.A. Neri, R. Colás, S. Valtierra, J. of Mat. Eng. and Performance 7467 (1998).

[15] A. Rrosen, A. Taub, ACTA METALLURGICA, 10501 (1962).

[16] D.V. Edmonds, Durban, South Africa, Physical, Materials and Earth Sciences, Microscopy Society of Southern Africa, 1. 667 (2002)

[17] Hugh O. Pierson, Handbook of Carbon, Graphite, Diamond and Fullerenes Properties, Processing and Applications, Consultant and Sandia National Laboratories (retired) Albuquerque, New Mexico, Published by William Andrew Inc. (1993) 100-104.

[18] ASM Metals HandBook Volume 1, Properties and Selection: Irons, Steels and High-Performance Alloys (1998) 13-194.

[19] A.R. Kiani-Rashid, D.V. Edmonds, Materials Sci. \& Eng. A, 481-482, 752 (2008)

[20] Iwamoto Takashi, Murakami Toshiyuki, JFE GIHO No. 464 (2004)

[21] K. He, A. Brown, R. Brydson, D. V. Edmonds, J. of Mat. Sci. 41 5235(2006)

[22] K. He, H.R. Daniels, A. Brown, R. Brydson, D.V. Edmonds, Acta Materialia 55 2919(2007)

[23] A.R.Kiani-Rashid, J. of Alloys and Compounds 470323 (2009) 


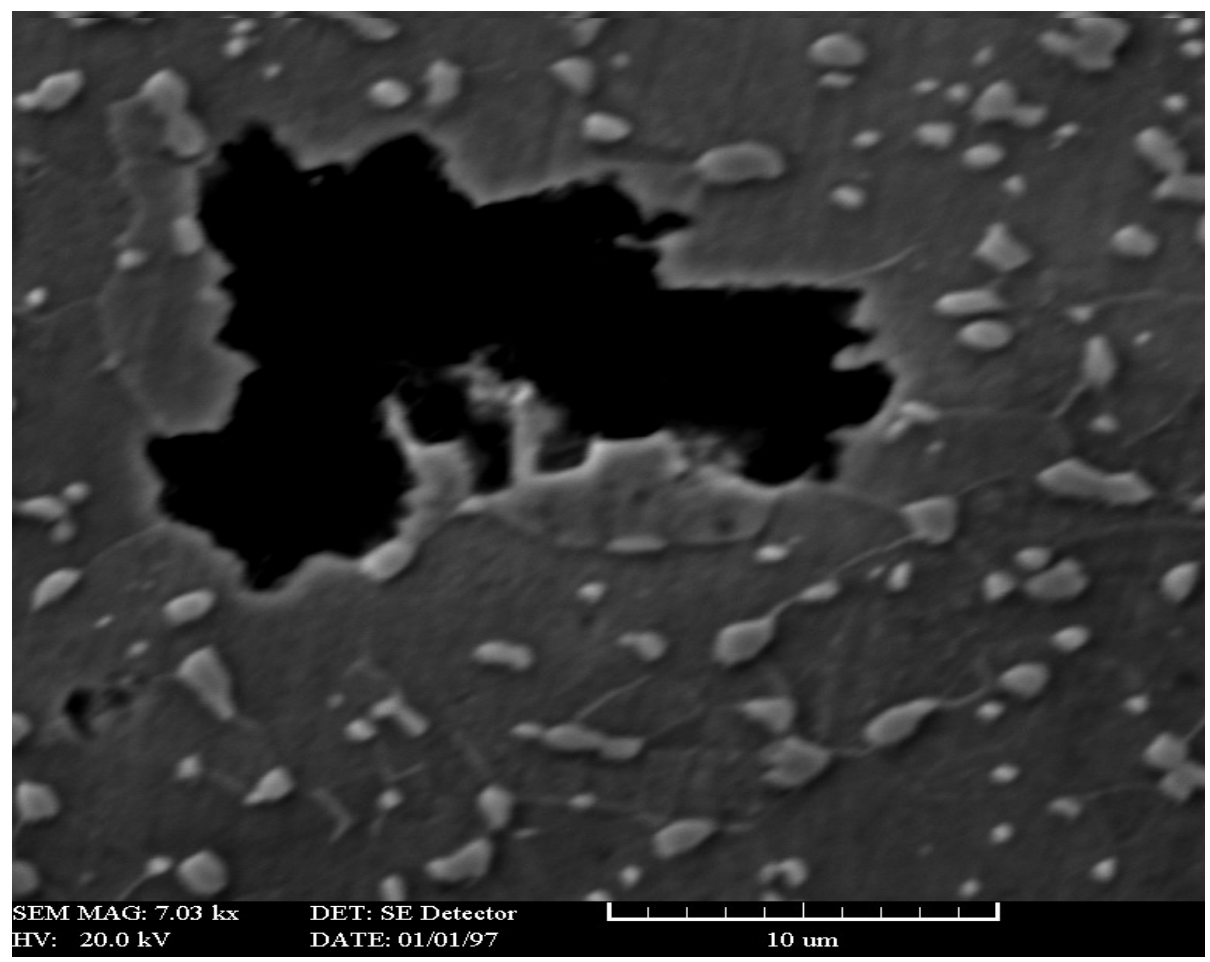

Fig. 5. SEM image from a graphite particle in CK100 steel after graphitization, (related to specimen 3)

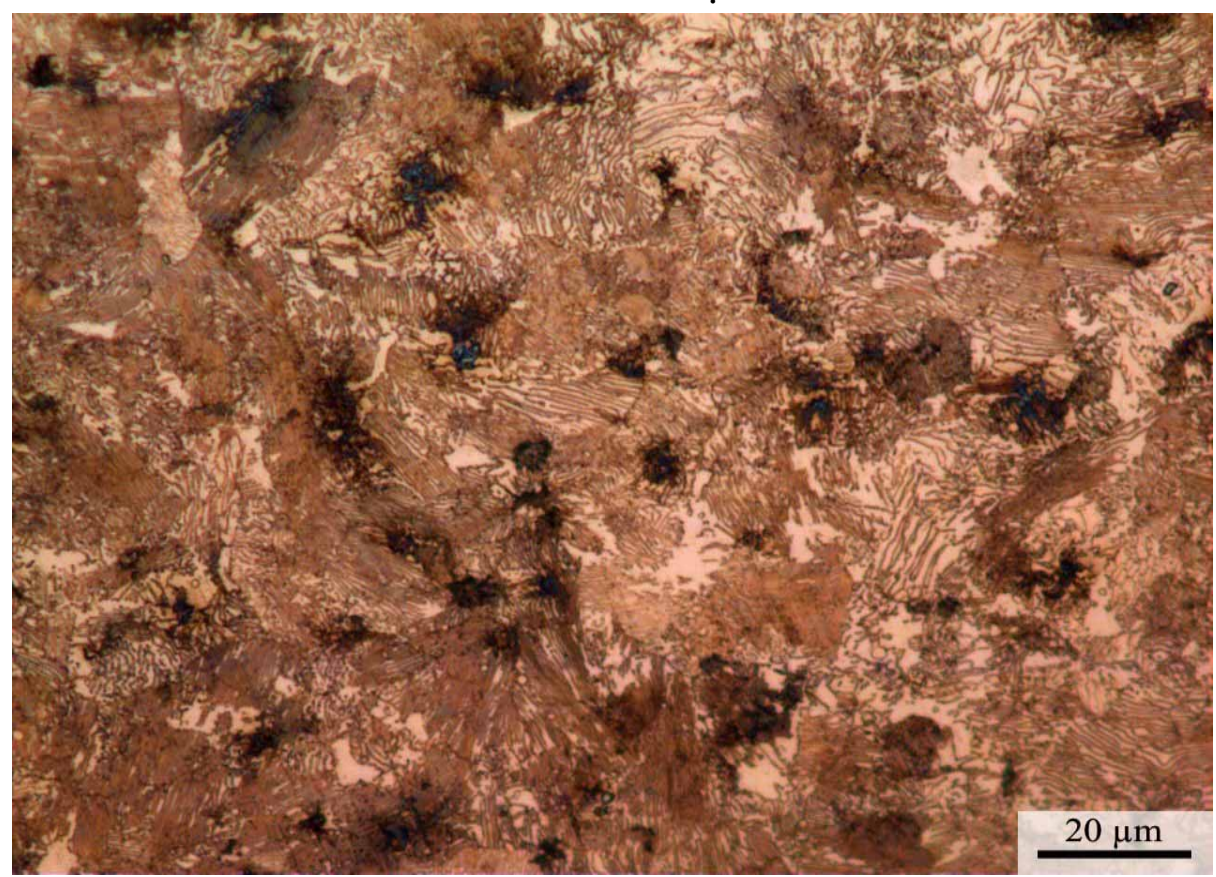

Fig. 6. Pearlitic-graphitic structure related to specimen 5. 


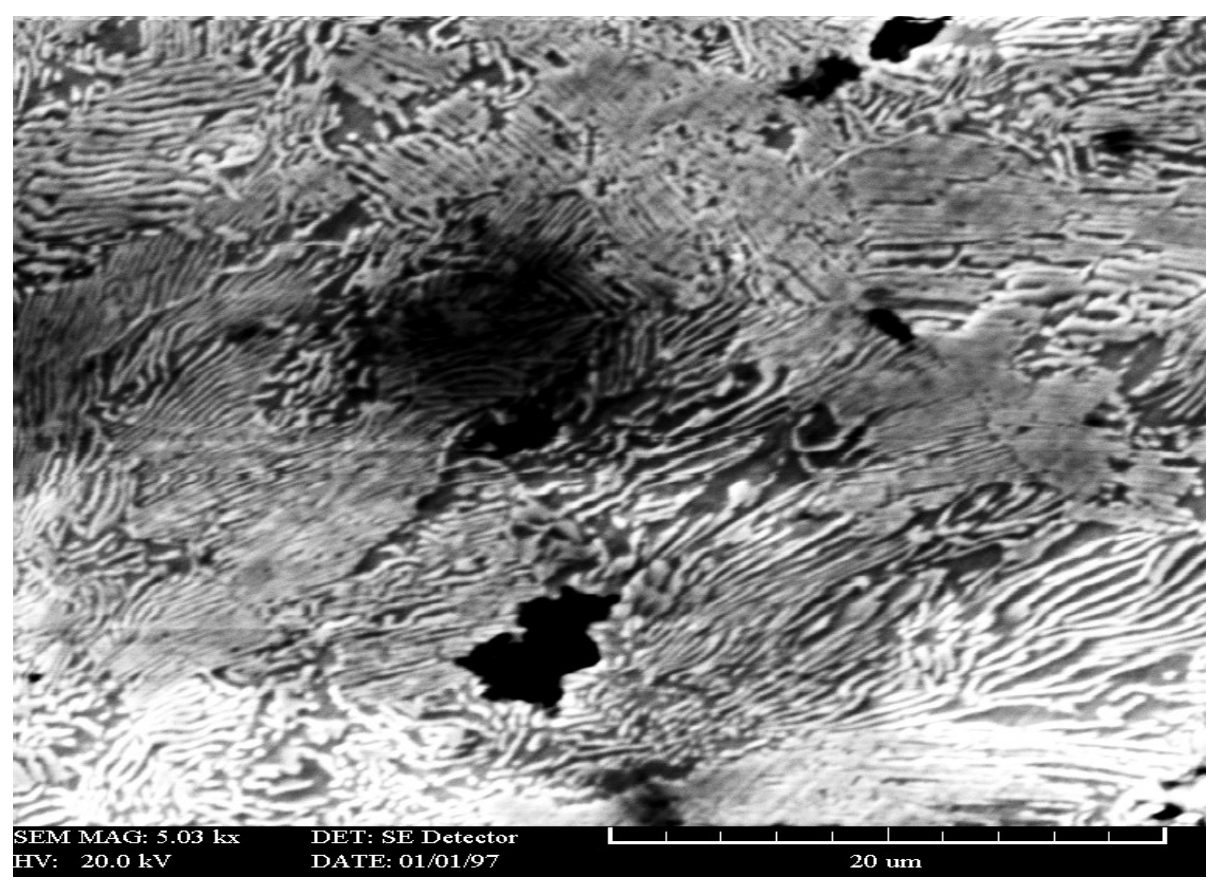

Fig. 7. SEM image from pearlitic-graphitic related to specimen 5. Pearlite colonies clearly are considered around graphite particles.

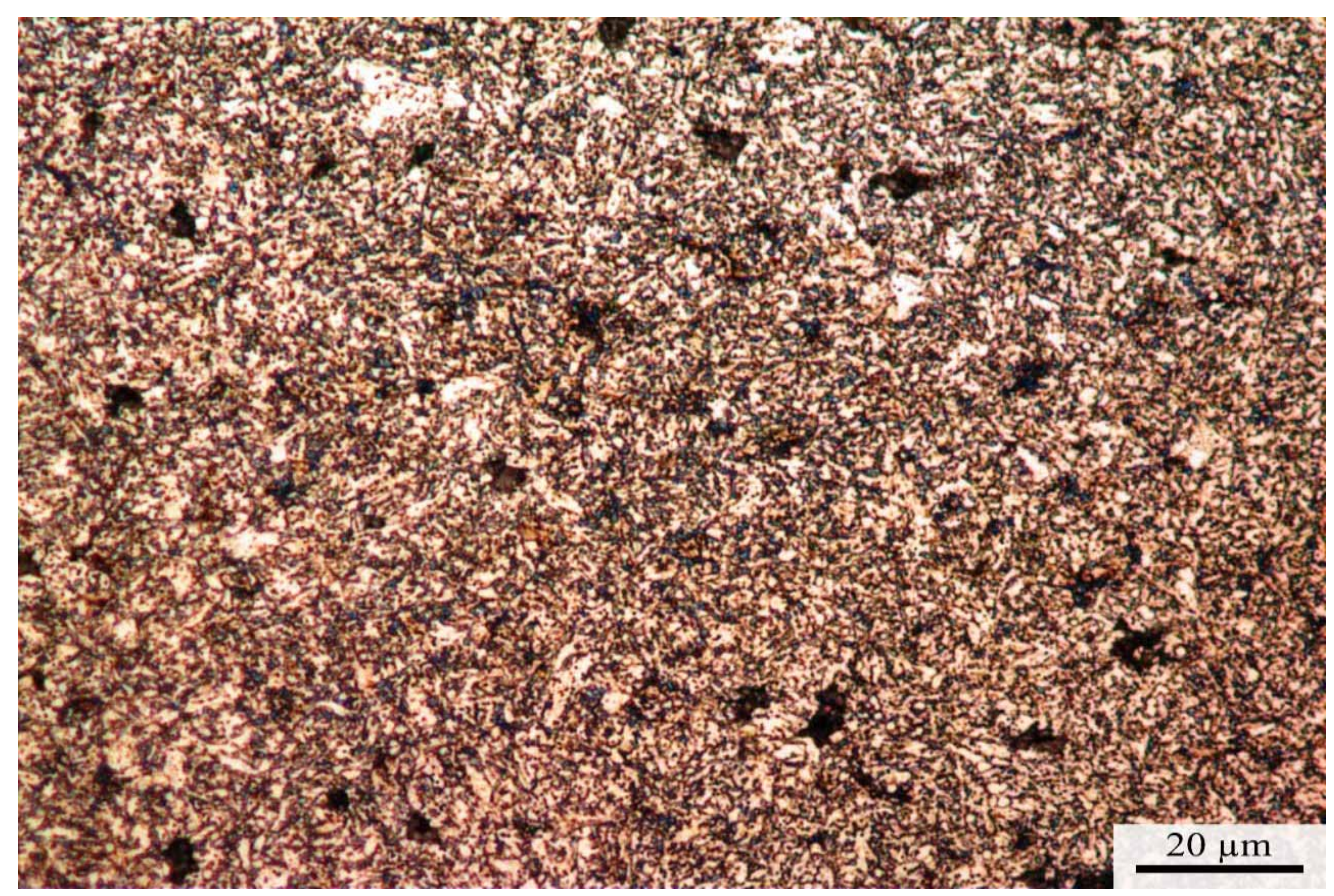

Fig. 8. Tempered martensite structure consists of small cementite particles in fine grained ferritic matrix related to specimen 6. 


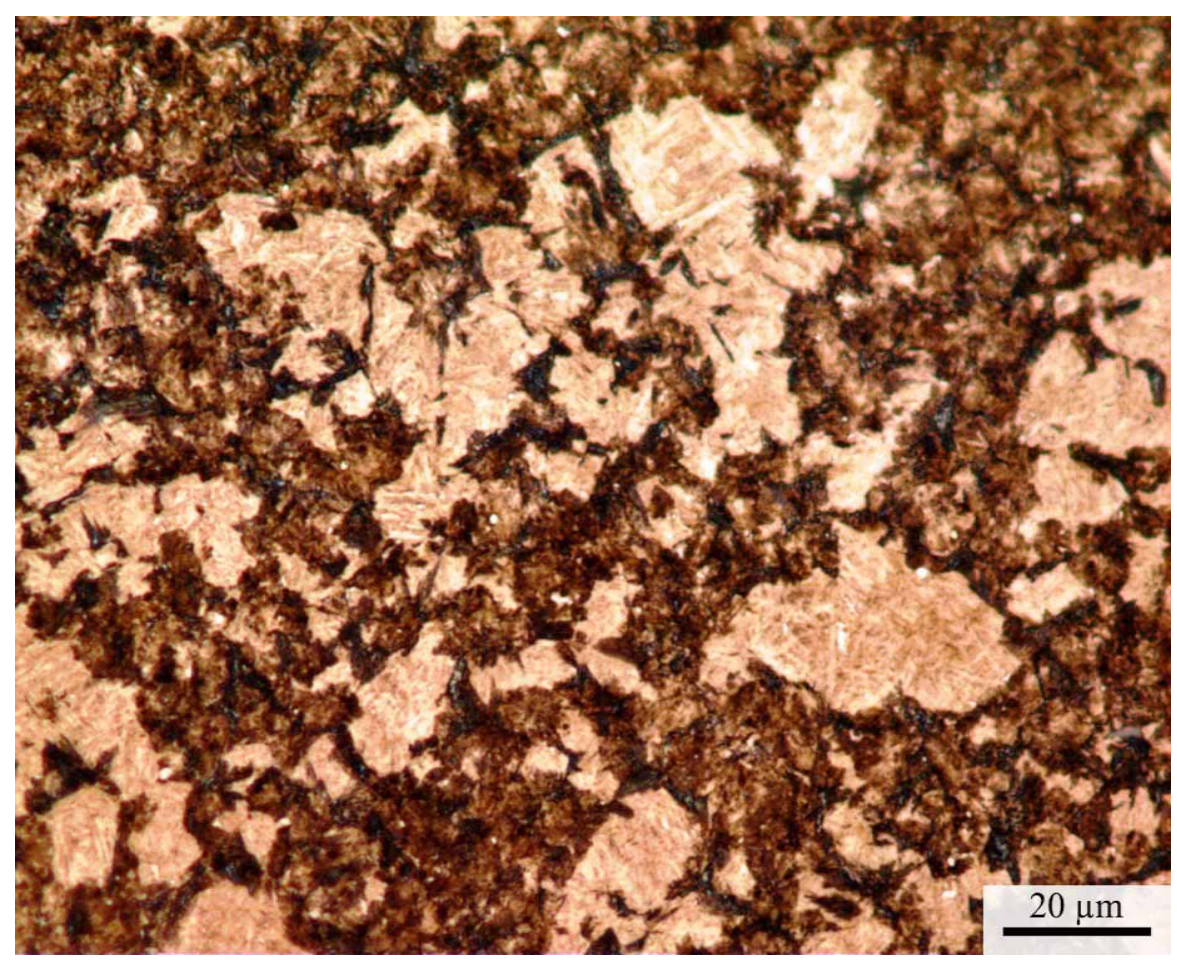

A

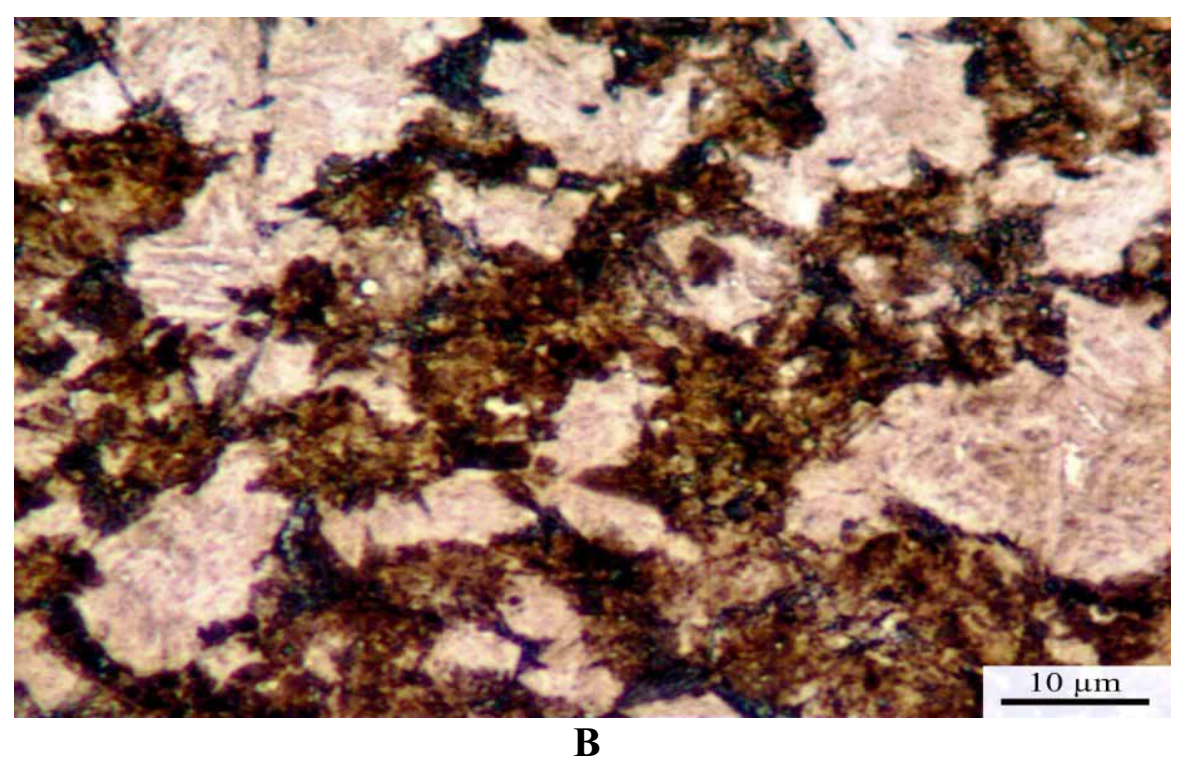

Fig. 9. Upper bainitic-graphitic structures related to specimen 7. A; dark phase illustrates upper bainite and bright phase is martensite which is produced during specimen cooling in air. B; The same structure with more magnificent. Needle like ferrite of upper bainite grows in structure. 


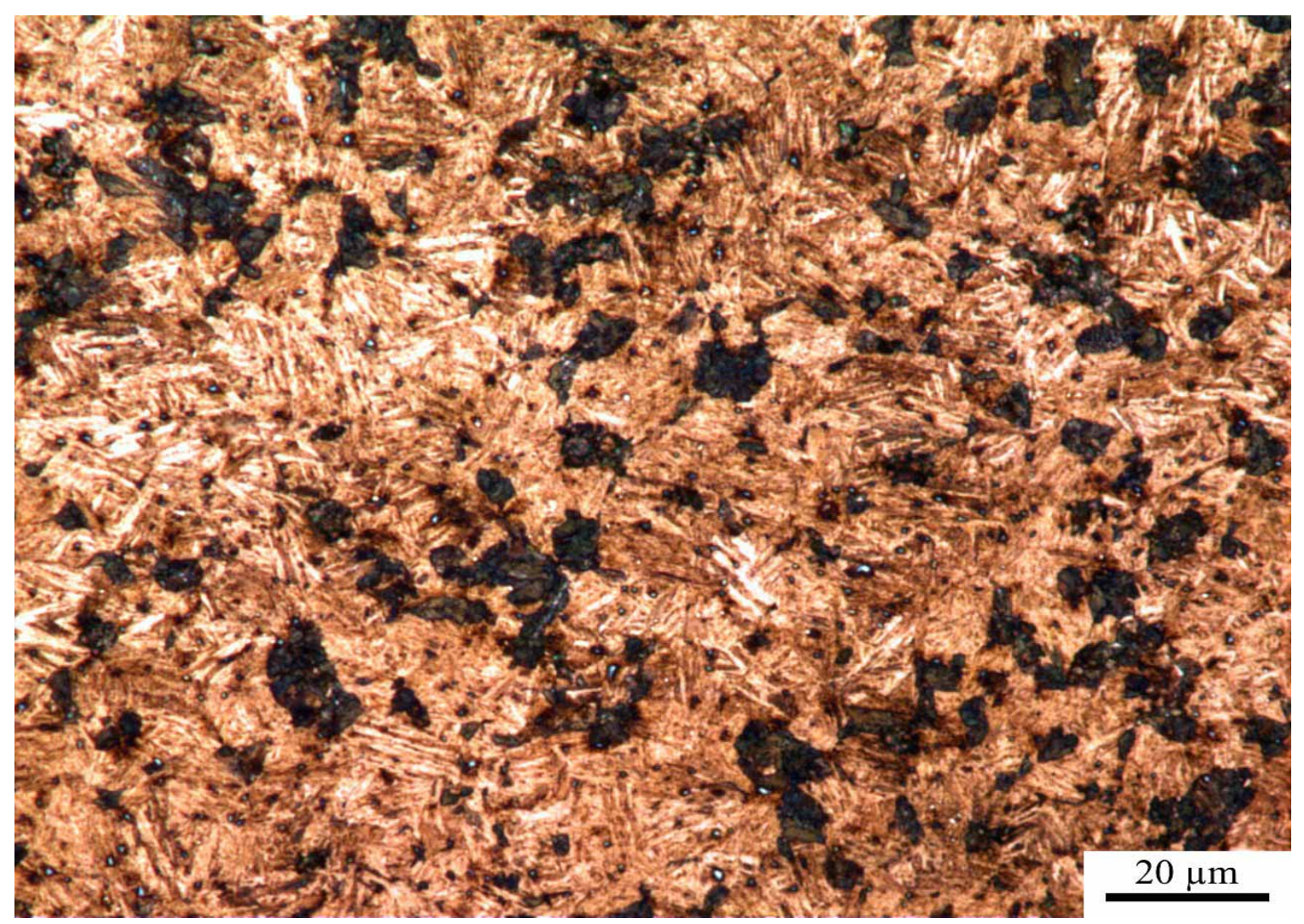

Fig. 10. Lower bainitic-graphitic structure related to specimen 8 . 